\title{
Styrene removal from polluted air in one and two-liquid phase biotrickling filter: Steady and transient-state performance and pressure drop control
}

Eldon R. Rene, María Montes, María C. Veiga, Christian Kennes

Bioresource Technologye, Volume102, Issue 13, 2011, Pages 9791- 9800.

DOI: 10.1016/j.biortech.2011.04.010

\section{Abstract}

A Sporothrix variecibatus-inoculated biotrickling filter (BTF) was examined for styrene removal, without and with the addition of silicone oil, at different empty bed residence times. The highest elimination capacities (ECs) were 172.8 (without silicone oil) and $670 \mathrm{~g} \mathrm{~m}^{-3} \mathrm{~h}^{-1}$ (with silicone oil), respectively, corresponding to a 4-fold improvement in presence of oil. The addition of silicone oil formed a well-coalesced emulsion of fungi and silicone oil, resulting in filter-bed clogging. Clogging prevention strategies adopted were; (i) lowering the volume ratio of silicone oil from $10 \%$ to $2 \%(\mathrm{v} / \mathrm{v})$, and (ii) periodic increase in trickling rate of the medium from 50 to $190 \mathrm{~mL} \mathrm{~min}^{-1}$. During shock-load experiments, the BTF with silicone oil (2\% v/v) could withstand high styrene loads, of up to $1900 \mathrm{~g} \mathrm{~m}^{-3} \mathrm{~h}^{-1}$, when compared to the BTF without silicone oil $\left(400 \mathrm{~g} \mathrm{~m}^{-3} \mathrm{~h}^{-1}\right)$.

\section{Keywords}

Biotrickling filter; Pressure drop; Sporothrix variecibatus; Styrene; Volatile organic compound.

\section{Introduction}

The ubiquitous presence of volatile organic compounds (VOCs) in the atmosphere has not only deteriorated air quality but has also caused unavoidable and immitigable adverse environmental impacts. Styrene (vapor pressure of $0.6 \mathrm{kPa}$ at $20^{\circ} \mathrm{C}$ ) is an important VOC, predominantly emitted from plastic manufacturing and polymer industries. Continuous exposure to small quantities of styrene has shown to cause neurotoxic, hematological, cytogenetic, and carcinogenic effects in humans (Dowty et al., 1976). Recent literature suggests that biodegradation of gas-phase styrene and other VOCs in bioreactor configurations such as biofilters (BFs) and biotrickling filters (BTFs) is a promising, efficient and safe technique for treating moderately high inlet loading rates (ILR) in comparison to different physico-chemical techniques (Kennes and Veiga, 2001, Djeribi et al., 2005, Avalos-Ramirez et al., 2009, Ramírez et al., 2009, Paca et al., 2009, Rene et al., 2009, Chen et al., 2010, Shukla et al., 2010 and Zilli et al., 2010). However, during the biotreatment of a hydrophobic VOC such as styrene, very high elimination capacities (ECs) are often not reached in BTFs due to the limitations arising from its low solubility in water $\left(300 \mathrm{mg} \mathrm{L}^{-1}\right)$ and its apparent toxicity towards biomass at high concentrations (Kirk-Othmer, 1983 and Dumont et al., 2006). In order 
to overcome these constraints, the addition of a water-immiscible organic solvent to the aqueous phase (bi-phasic) has been suggested or even the addition of absorbing polymers (Kennes et al., 2009 and Montes et al., 2011). Styrene would serve as a good prospect for degradation in bi-phasic systems, since high concentrations and large surface areas could be achieved by mixing styrene (gas-phase) in the dispersed organic phase.

Though BTFs have been operated extensively with great success for VOC removal, their application with the addition of a non-aqueous phase liquid like silicone oil to the trickling medium has only been explored recently and very little information is available on its long-term performance (Djeribi et al., 2005, Bailón et al., 2009 and Montes et al., 2010). In these recent BTFs, a mixture of an organic solvent and water (mineral medium) is continuously trickled over the packed bed, while the contaminated air stream flows either co-currently or counter-currently to the liquid. The gas-phase pollutant is then absorbed in the organic phase (oil-phase), transferred to the microorganisms at sub-inhibitory levels and then subsequently biodegraded (Daugulis, 1997, Kennes and Veiga, 2001, van Groenestijn and Kraakman, 2005, Muñoz et al., 2006, Arriaga et al., 2006, Aldric and Thonart, 2008 and Montes et al., 2010).

Biological waste-gas treatment systems inoculated with fungi have been reported to be more efficient compared to systems inoculated with bacterial cultures (van Groenestijn et al., 2001, Arriaga and Revah, 2005, Rene et al., 2010a and Rene et al., 2010b). The mycelium of fungi has the capability to uptake hydrophobic compounds faster than flat aqueous bacterial biofilm surfaces (van Groenestijn and Kraakman, 2005 and Kennes and Veiga, 2004). van Groenestijn and Kraakman (2005) reported that fungi possess relatively large surface areas of the mycelia, and the use of fungi in a BF can increase the EC up to 5-10 times compared to conventional compost BFs. Sporothrix variecibatus used in this study, is a fast growing styrene degrading yeast-like fungus that has shown good potential to utilize gas-phase styrene in BF and monolith bioreactors ( Rene et al., 2010a and Rene et al., 2010b).

There are only a few published papers pertaining to the use of two-liquid phases in BTFs for the treatment of gas-phase VOCs. As a continuity of our original research plans to develop high performance fungal bioreactors for styrene removal, a lava rock BTF was tested without and with silicone oil in order to address the mass transfer limitation problems. Shock withstanding tests were also conducted to assess the response and stability of the BTF to handle transient-state operations, with and without silicone oil.

\section{Methods}

\subsection{Chemicals used}

The mineral salt medium ( $\mathrm{pH}$ 5.9) was prepared according to the chemical composition described elsewhere (Estévez et al., 2005). Analytical grade styrene and silicone oil (DC200; viscosity: $10 \mathrm{mPa}$ s; density: $1.05 \mathrm{~g} \mathrm{~mL}^{-1}$; vapor pressure $<5 \mathrm{mmHg}$; ${ }^{20} \mathrm{nD} 20$ : 1.401@ $25^{\circ} \mathrm{C}$ ) used in the study were purchased from Sigma-Aldrich Chemicals, USA. 


\subsection{Microorganism and inoculum preparation}

Sporothrix variecibatus was grown on $15 \mathrm{~g}_{\text {agar }} \mathrm{L}^{-1}$, in petri dishes and maintained in a desiccator containing gas-phase styrene. The fungus was aseptically transferred to two $1000 \mathrm{~mL}$ airtight Erlenmeyer-flasks (working volume - $250 \mathrm{~mL}$ ), having an initial gasphase styrene concentration of $\sim 15 \mathrm{~g} \mathrm{~m}^{-3}$ at $30^{\circ} \mathrm{C}$, and maintained under constant shaking $(175 \mathrm{rpm})$. After $48 \mathrm{~h}$, when the optical density $\left(\mathrm{OD}_{\lambda-600}\right)$ reached 0.8 , the cells were harvested by centrifugation at $5000 \mathrm{rpm}$ for 15-min and re-suspended in $2 \mathrm{~L}$ fresh nutrient medium to be used as inoculum for the continuous BTF. About $1000 \mathrm{~mL}$ of this culture was added to the BTF from the top; the leachate was collected in a collection tank and then recirculated at $50 \mathrm{~mL} \mathrm{~min}{ }^{-1}$ continuously for the next $24 \mathrm{~h}$. The same procedure was repeated with the remaining $1000 \mathrm{~mL}$ medium containing the pure culture.

\subsection{BTF setup and operation}

Fig. 1 shows the schematic of the experimental BTF. The operational characteristics were quite similar to the BTF previously operated and reported for treating gas-phase dichloromethane (Bailón et al., 2009). The reactor column, made of glass, was $0.1 \mathrm{~m}$ diameter $\times 0.7 \mathrm{~m}$ tall. The BTF was packed with lava rock grains to a height of $0.24 \mathrm{~m}$ (working bed volume $-0.0019 \mathrm{~m}^{3}$ ), and both the gas-phase styrene and the trickling nutrient medium, without and with silicone oil, were fed co-currently to the reactor in a downflow mode. A nutrient hold tank, filled with $1.35 \mathrm{~L}$ nutrient medium and $150 \mathrm{~mL}$ silicone oil (organic/aqueous ratio of 1:9), was well-mixed using a magnetic stirrer, and was continuously fed to the BTF at a flow rate of $50 \mathrm{~mL} \mathrm{~min}^{-1}$ using a peristaltic pump (Watson and Marlow, USA). The $\mathrm{pH}$ of the recirculated nutrient medium was maintained constant, at 5.9, by means of a pH electrode (EASYFERM 120, Hamilton) attached to the nutrient collection tank and a controller coupled to an electro valve (DO 9765T, Dual 31/2 Digit pH redox indicator and regulator, Italy), by dosing a $2 \mathrm{~N} \mathrm{NaOH}$ solution to neutralize the acidic metabolites formed during the biodegradation process. When required, $10 \mu \mathrm{L}$ Tween 80 was added to reduce foaming in the nutrient hold tank. To prevent redundant ions from accumulating in the tank, and to avoid nutrient limitations, the entire aqueous and oil-phase was discarded, and was refilled with fresh nutrient medium and oil, once every four weeks. Besides, whenever the volume of the water-phase decreased in the hold tank, due to evaporation, the required amount of medium was added to maintain a constant organic/aqueous phase ratio. All tubings were made of solvent resistant Viton rubber. Styrene concentrations were varied from 0.1 to $24 \mathrm{~g} \mathrm{~m}^{-3}$, by mixing the different gas streams (air and pollutant) in a mixing chamber. The gas-flow rates were set at $0.075,0.15$, and $0.34 \mathrm{~m}^{3} \mathrm{~h}^{-1}$, corresponding to empty bed residence times (EBRTs) of 91.2, 40.2, and $20.1 \mathrm{~s}$, respectively. The pressure drop $(\Delta P)$ across the BTF was measured using a differential U-tube water manometer having an operational range of $0-40 \mathrm{~cm} \mathrm{H}_{2} \mathrm{O}$. 


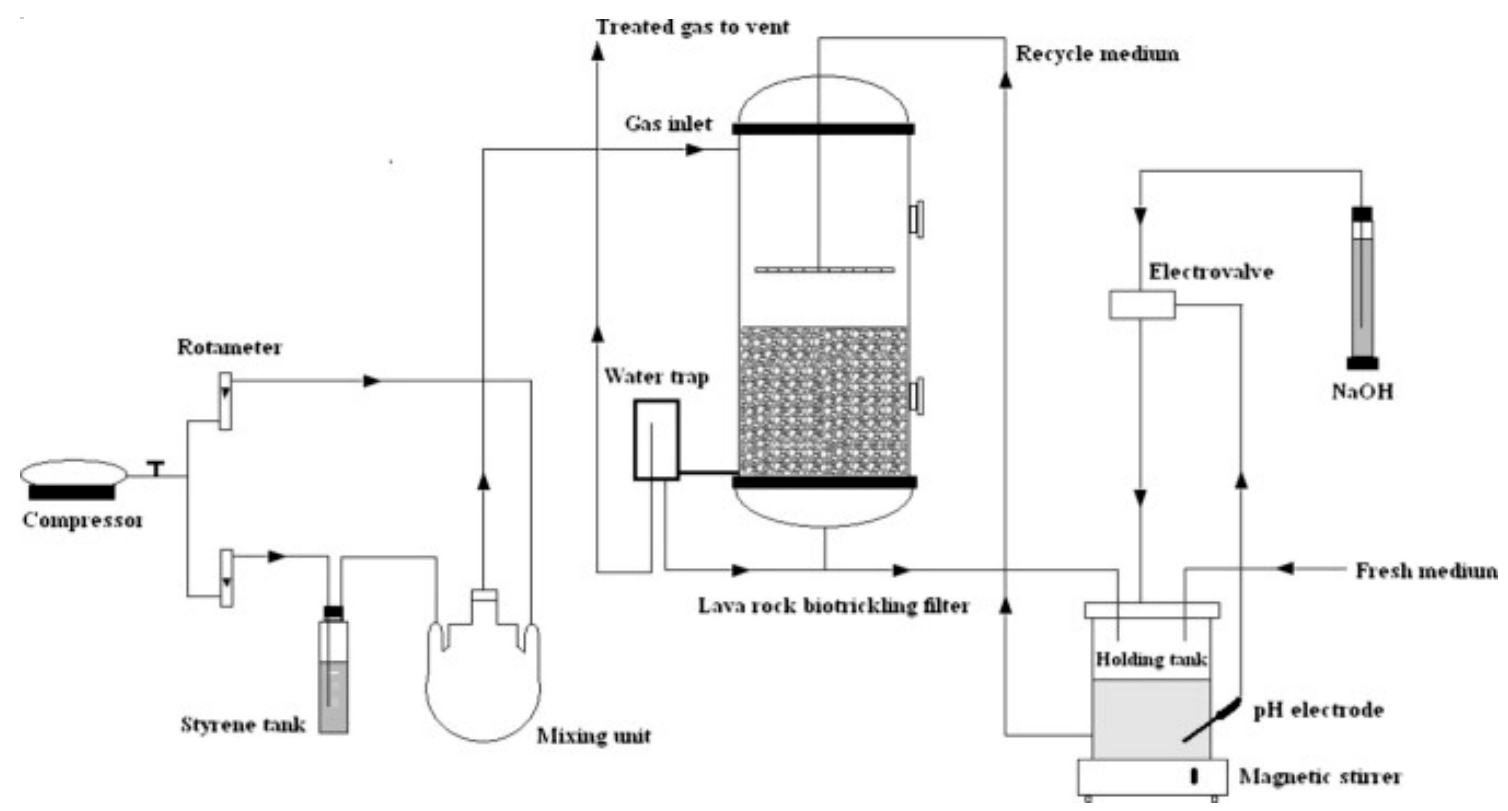

Fig. 1.

Schematic of the BTF treating gas-phase styrene.

\subsection{Analytical methods}

Gas-phase samples collected from the inlet and exit sampling ports were subjected to chromatographic analysis for styrene quantification, on a HP 6890 gas chromatograph, using a $50 \mathrm{~m}$ TRACER column (L-50 m; phase: TR Wax; ID: $0.32 \mathrm{~mm}$; film: $1.2 \mu \mathrm{m}$ ) and a FID. The flow rates were $30 \mathrm{~mL} \mathrm{~min}^{-1}$ for $\mathrm{H}_{2}$ and $300 \mathrm{~mL} \mathrm{~min}^{-1}$ for air. Helium was used as the carrier gas at a flow rate of $2 \mathrm{~mL} \mathrm{~min}^{-1}$. The temperatures at the GC injection, oven and detection ports were 250,120 and $250{ }^{\circ} \mathrm{C}$, respectively. $\mathrm{CO}_{2}$ was analyzed with a HP 5890 series II gas chromatograph equipped with a TCD (Rene et al., 2009).

\section{Results and discussion}

\subsection{Performance at different EBRTs without silicone oil}

After acclimation (28 days), the combined effect of styrene inlet concentration and gasflow rate was investigated in three different phases (EBRTs: 91.2, 40.2 and $20.1 \mathrm{~s}$ ) (Fig. 2a). The corresponding gas to liquid (G/L) ratios were 25, 53 and 113 , respectively, corresponding to commonly used ratios in BTFs (Kennes et al., 2009). 

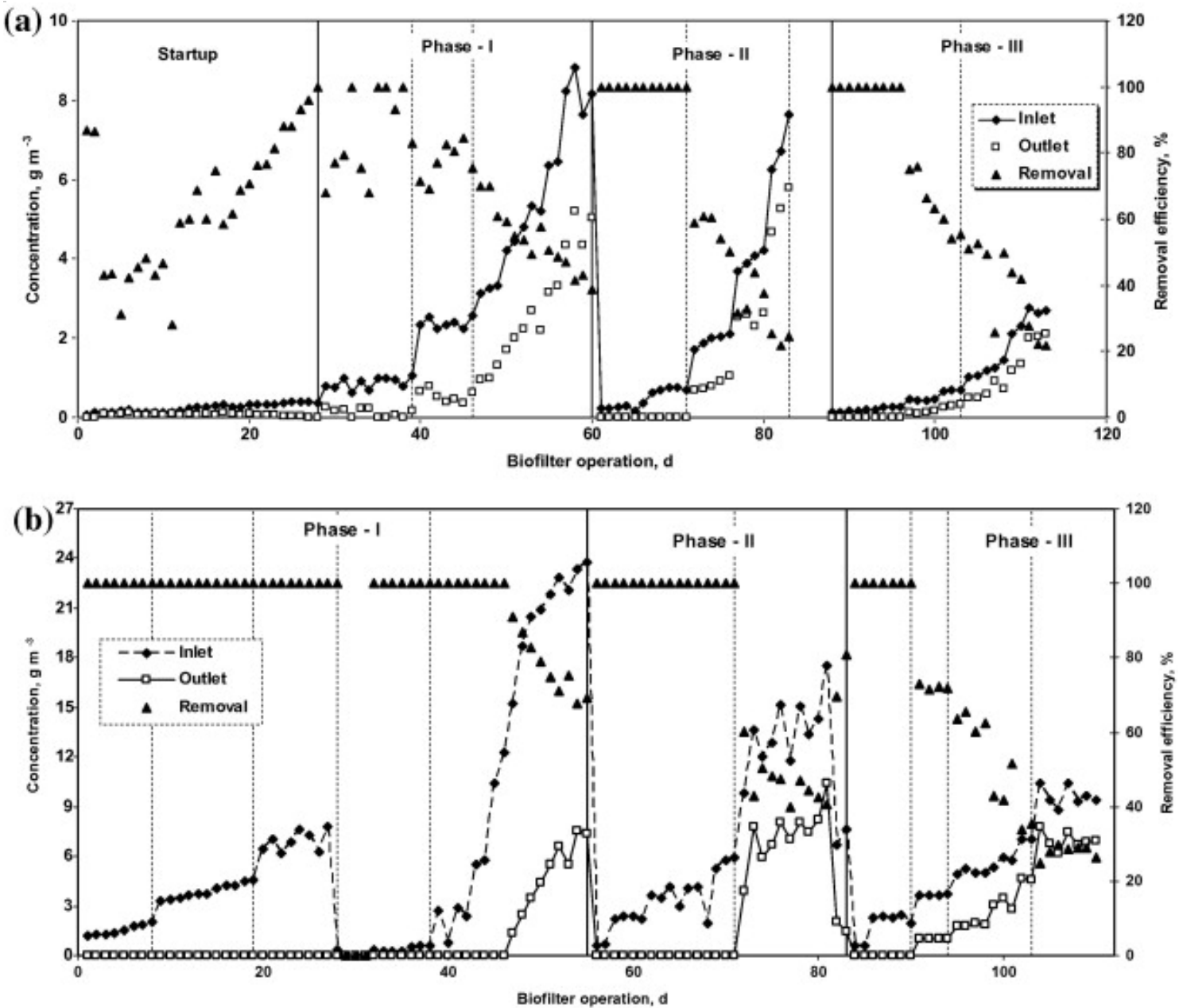

Fig. 2.

Removal of gas-phase styrene in the fungal BTF (Phases I-III), (a) without silicone oil, and (b) with silicone oil.

In phase-I, the styrene concentration was first increased and then maintained almost constant, between 0.7 and $1 \mathrm{~g} \mathrm{~m}^{-3}$, during the first 10 days, at an EBRT of $91.2 \mathrm{~s}$. A removal efficiency (RE) of $>90 \%$ was reached at the end of the start-up phase, from the 29th day. The concentration was then increased, from 1 to $2.6 \mathrm{~g} \mathrm{~m}^{-3}$ and maintained constant thereafter (days 39-46) at $2.6 \mathrm{~g} \mathrm{~m}^{-3}$, with a nearly constant removal efficiency (RE) of around $80 \%$. In order to estimate the maximum performance of the fungal BTF, the concentration was later gradually increased from 2.6 to as high as $8.9 \mathrm{~g} \mathrm{~m}^{-3}$ (Fig. 2a). For concentrations lower than $5 \mathrm{~g} \mathrm{~m}^{-3}, \mathrm{RE}>60 \%$ could easily be maintained. On the other hand, concentrations $>5 \mathrm{~g} \mathrm{~m}^{-3}$ led to a rapid drop in the RE from $>60 \%$ to $38 \%$.

During phase-II, at an EBRT of $40.2 \mathrm{~s}$, the concentration was first decreased from $>8 \mathrm{~g} \mathrm{~m}^{-3}$, the previously fed high values in phase-I, to $0.2 \mathrm{~g} \mathrm{~m}^{-3}$. The styrene concentration in this phase was lowered in order to improve the performance of the BTF and the activity of the fungus, that was earlier subjected to high styrene concentrations in Phase-I. It can be seen from Fig. 2a, that the RE was almost $100 \%$ from days 61 to 71. Later, on day 72, the concentration of styrene was increased step-wise in order to estimate the maximum BTF performance. The concentration was increased from 0.8 to $1.7 \mathrm{~g} \mathrm{~m}^{-3}$, then from 1.7 to $4 \mathrm{~g} \mathrm{~m}^{-3}$, and finally to values greater than $6 \mathrm{~g} \mathrm{~m}^{-3}$. Though 
high RE were maintained (100\%) during the initial 11 days, an increase in the concentration to $>2 \mathrm{~g} \mathrm{~m}^{-3}$ showed a declining trend in the RE profile. For concentrations $>6 \mathrm{~g} \mathrm{~m}^{-3}$, the RE dropped to values as low as $20 \%$.

The concentrations of styrene were kept lower in phase-III (Fig. 2a) in comparison to their concentrations in the previous two phases since the BTF was operated at a gasflow rate of $0.34 \mathrm{~m}^{3} \mathrm{~h}^{-1}$ (lower EBRT of $20.1 \mathrm{~s}$ ), and a G/L ratio of 113. The BTF was initially subjected to styrene concentrations $<0.3 \mathrm{~g} \mathrm{~m}^{-3}$ for the first 9 days, in order to restore the high performance of the BTF. When the concentration was increased thereafter, from 0.8 to $2.7 \mathrm{~g} \mathrm{~m}^{-3}$, the RE gradually dropped, reaching $53 \%$ at an inlet concentration of $1.1 \mathrm{~g} \mathrm{~m}^{-3}$, corresponding to a load of $211 \mathrm{~g} \mathrm{~m}^{-3} \mathrm{~h}^{-1}$, and $21 \%$ at an inlet concentration of $2.7 \mathrm{~g} \mathrm{~m}^{-3}$ (ILR- $493 \mathrm{~g} \mathrm{~m}^{-3} \mathrm{~h}^{-1}$ ). Despite the supply of low styrene concentrations in this phase, high gas-flow rates led to higher ILRs and thus lower REs than in previous phases.

\subsection{Performance at different EBRTs with silicone oil}

In order to compare the reactors performance, with and without oil, the adapted biomass from the experiment without silicone oil was used for studies in presence of oil. Therefore, no acclimation was required. For the sake of comparing the results, BTF experiments with silicone oil were also carried out in three different phases, maintaining the same EBRTs as that for the BTF without silicone oil, i.e. $91.2 \mathrm{~s}$ (days 1-55), $40.2 \mathrm{~s}$ (days 55-83), and 20.1 s (days 84-110), as shown in Fig. 2b.

Phase-I (EBRT - $91.2 \mathrm{~s}$ ) was started with 10\% silicone oil. During the first 8 days, styrene concentrations were $<2 \mathrm{~g} \mathrm{~m}^{-3}$, and the $\mathrm{RE}$ was $100 \%$. An increase in styrene concentration did not seem to affect the RE of the BTF and high RE's were consistently maintained throughout this phase even at the highest loading rate of $306 \mathrm{~g} \mathrm{~m}^{-3} \mathrm{~h}^{-1}$. The BTF was then shut-down for maintenance, from days 28 to 31, due to an increase in $\Delta P$, as a result of the presence of an oil-biomass emulsion. The different strategies adopted to avoid $\Delta P$ are discussed later. The operation was resumed on the 32nd day by reducing the amount of silicone oil in the aqueous phase to $2 \% \mathrm{v} / \mathrm{v}$, with low styrene concentrations in order to achieve higher REs (100\%), and this concentration $\left(<0.6 \mathrm{~g} \mathrm{~m}^{-3}\right)$ was maintained until day 38. In the next step (days 39-55), in order to determine the $\mathrm{EC}_{\max }$ of the $\mathrm{BTF}$ at this EBRT, the concentration was progressively increased from $\sim 2.5$ (day 39) to $23.8 \mathrm{~g} \mathrm{~m}^{-3}$ (day 55). An increase in the styrene concentration during this stage did initially not affect the RE, even slightly, and $100 \%$ $\mathrm{RE}$ was maintained for concentrations up to $12.3 \mathrm{~g} \mathrm{~m}^{-3}$. An increase in the concentration beyond $12.3 \mathrm{~g} \mathrm{~m}^{-3}$, between days 47 and 55, decreased the RE by just $30 \%$. At the highest concentration tested in phase-I $\left(23.8 \mathrm{~g} \mathrm{~m}^{-3}\right)$, i.e., when the ILR was $940 \mathrm{~g} \mathrm{~m}^{-3} \mathrm{~h}^{-1}$, the RE was $\sim 70 \%$. In previous works, at the same EBRT, a BF and a monolith bioreactor, operated without the addition of silicone oil, were only able to handle concentrations of 0.1-14, and 0.1-2.5 $\mathrm{g} \mathrm{m}^{-3}$, respectively, and the RE decreased significantly when the concentrations were at their respective highest ( Rene et al., 2010a and Rene et al., 2010b). The ability of the BTF to handle high styrene concentrations, in the presence of silicone oil and the attached fungi on the packing, can be attributed to the high solubility (absorption) of styrene in silicone oil (30,000 mg L${ }^{-1}$ ) as reported by Dumont et al. (2006), and the subsequent styrene uptake by the fungus Sporothrix spp., in the bi-phasic trickling medium that undergoes direct assimilation 
from the gas-phase as well as through the observed contact between the fungi and the silicone oil ( Arriaga et al., 2006).

The concentration of styrene was increased from 0.6 to $6 \mathrm{~g} \mathrm{~m}^{-3}$ for the first 16 days, in phase-II (EBRT - 40.2 s), in three small time steps, and it was observed that the RE remained constant $(100 \%)$, despite being subjected to very high concentrations in the previous phase. From days 72 to 91 , the concentrations were once again increased linearly up to $17.5 \mathrm{~g} \mathrm{~m}^{-3}$, corresponding to an ILR of $1760 \mathrm{~g} \mathrm{~m}^{-3} \mathrm{~h}^{-1}$, to envisage the $\mathrm{EC}_{\max }$ of the BTF. The RE dropped by $\sim 40 \%$ when the concentration was increased from 6 to $9.8 \mathrm{~g} \mathrm{~m}^{-3}$, and a further increase in concentration decreased the RE (40-60\%). Thus, the decline in RE was clearly due to an increase in the gas-flow rate, i.e., lower EBRT compared to the previous phase, and not because of styrene concentrations. As already recalled for the BTF without silicone oil, decreasing the EBRTs has shown to cause significant effect on the pollutant removal characteristics in BFs and BTFs, despite similar values of inlet pollutant concentration ( Kennes and Veiga, 2001 and Djeribi et al., 2005).

Phase-III was tested for 27 days, at relatively lower styrene concentrations than in phase I and II, at a gas-flow rate of $0.34 \mathrm{~m}^{3} \mathrm{~h}^{-1}$. Once again, like in the previous phase, the inlet concentration was reduced and maintained at lower values $\left(<2.5 \mathrm{~g} \mathrm{~m}^{-3}\right)$ for the first 7 days, which correspond to ILR $<435 \mathrm{~g} \mathrm{~m}^{-3} \mathrm{~h}^{-1}$. It can be seen from Fig. $2 \mathrm{~b}$ that the original reactor performance was easily restored (100\%), and thereafter, for the next 4 days, when the concentration was increased to $3.8 \mathrm{~g} \mathrm{~m}^{-3}$, the RE dropped to $72 \%$. A further increase in the concentration, gradually from 3.7 to $7 \mathrm{~g} \mathrm{~m}^{-3}$, led to an abrupt decline in the RE values and the RE dropped by almost 35\%. The reactor performance was at its lowest $(<27 \%)$, when the gas-phase styrene concentration was $>8 \mathrm{~g} \mathrm{~m}^{-3}$. The severe decline in RE at later stages in this phase ( $>100$ days operation) could be due to the subjection of the BTF to higher ILRs $\left(>1000 \mathrm{~g} \mathrm{~m}^{-3} \mathrm{~h}^{-1}\right)$, owing to which inhibition effects would have predominated and thus the RE dropped significantly.

\subsection{Carbon dioxide generation rate}

Carbon dioxide production rate $\left(\mathrm{P}_{\mathrm{CO} 2} \mathrm{PCO} 2, \mathrm{~g} \mathrm{~m}^{-3} \mathrm{~h}^{-1}\right)$ in the BTF was calculated using the formulae described elsewhere (Kennes et al., 2009). Fig. 3a and b show the correlations between $\mathrm{P}_{\mathrm{CO} 2} \mathrm{PCO} 2$ and the EC of the BTF, without and with silicone oil, observed during phases I-III. For complete chemical mineralization of styrene to $\mathrm{CO}_{2}$ and water, the ratio of $\mathrm{CO}_{2}$ produced to the amount of styrene consumed should be 3.4 (Jorio et al., 2000), according to the stoichiometric reactions mentioned elsewhere (Rene et al., 2010a). From the regression equations, $Y=3.05 X+59.772\left(R^{2}=0.663\right)$ without silicone oil and $Y=1.79 X+37.5\left(R^{2}=0.757\right)$ with silicone oil, it is clearly evident that the ratio of $\mathrm{CO}_{2}$ produced to the amount of styrene consumed was close to 3.05 and 1.79, the fraction of unaccounted $\mathrm{CO}_{2}$ could have been used for cellular growth and maintenance. It is noteworthy to mention that the variation between the unaccounted $\mathrm{CO}_{2}$ in the BTF with oil and the BTF without oil was certainly not due to the absorption of $\mathrm{CO}_{2}$ by the oil. Separate batch tests were conducted in $110 \mathrm{ml}$ air-tight glass vials, where the head-space $(100 \mathrm{ml})$ was saturated with $\mathrm{CO}_{2}$ and the remaining contained different proportions of oil/aqueous phase, to confirm this and no absorption of $\mathrm{CO}_{2}$ was observed (data not shown). The $\mathrm{P}_{\mathrm{CO} 2} \mathrm{PCO} 2 / \mathrm{EC}$ ratio observed in this study for BTF operation without silicone oil is comparable to the values reported in the literature for styrene degradation ( Rene et al., 2010a and Jorio et al., 2000). 

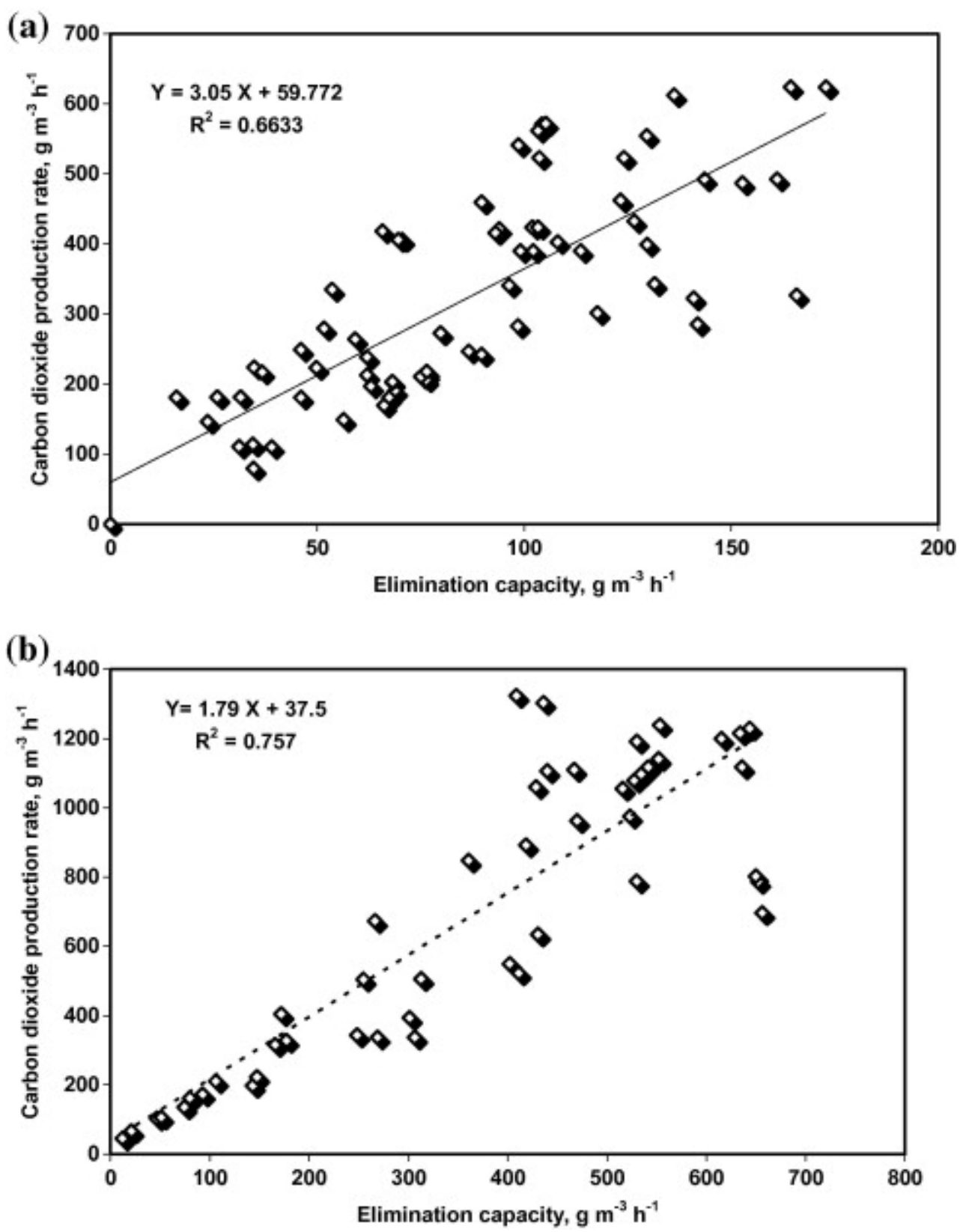

Fig. 3.

Relationship between carbon dioxide production rate and EC of the BTF, (a) without silicone oil, and (b) with silicone oil.

\subsection{Influence of ILR on the EC of BTF}

\subsubsection{Without silicone oil}

The EC is plotted as a function of the ILR in Fig. 4a. A near linear relation between the two variables was observed up to an ILR of $80 \mathrm{~g} \mathrm{~m}^{-3} \mathrm{~h}^{-1}$. However for higher initial concentrations tested in phases I-III, the EC of the filter bed increased at a slower rate, from 60 to $170 \mathrm{~g} \mathrm{~m}^{-3} \mathrm{~h}^{-1}$, to become nearly constant at $150 \mathrm{~g} \mathrm{~m}^{-3} \mathrm{~h}^{-1}$ for ILRs $>300 \mathrm{~g} \mathrm{~m}^{-3} \mathrm{~h}^{-1}$. This clearly shows two different operating regimes, as previously described in the literature, i.e. the diffusion limitation regime (DLR) and the reaction limitation regime (RLR) ( Jorio et al., 2000); (i) DLR- for ILRs $<80 \mathrm{~g} \mathrm{~m}^{-3} \mathrm{~h}^{-1}$, the EC 
increased linearly with an increase in ILR because the gas-biofilm interface is relatively small and complete mineralization of styrene occurred in the fungal biofilm, and (ii) RLR- when the ILR was $>80 \mathrm{~g} \mathrm{~m}^{-3} \mathrm{~h}^{-1}$, the EC remained almost constant and decreased slightly depending on the EBRT. In this zone, the biofilm is fully active and the RE of the pollutant is controlled only by the rate of biodegradation. The ILR to achieve $>90 \%$ RE (ILR critical $_{\text {) }}$ at an EBRT of 91.2, 40.2, and $20.1 \mathrm{~s}$ were found to be 94.5, 68.1, and $49.8 \mathrm{~g} \mathrm{~m}^{-3} \mathrm{~h}^{-1}$, respectively.
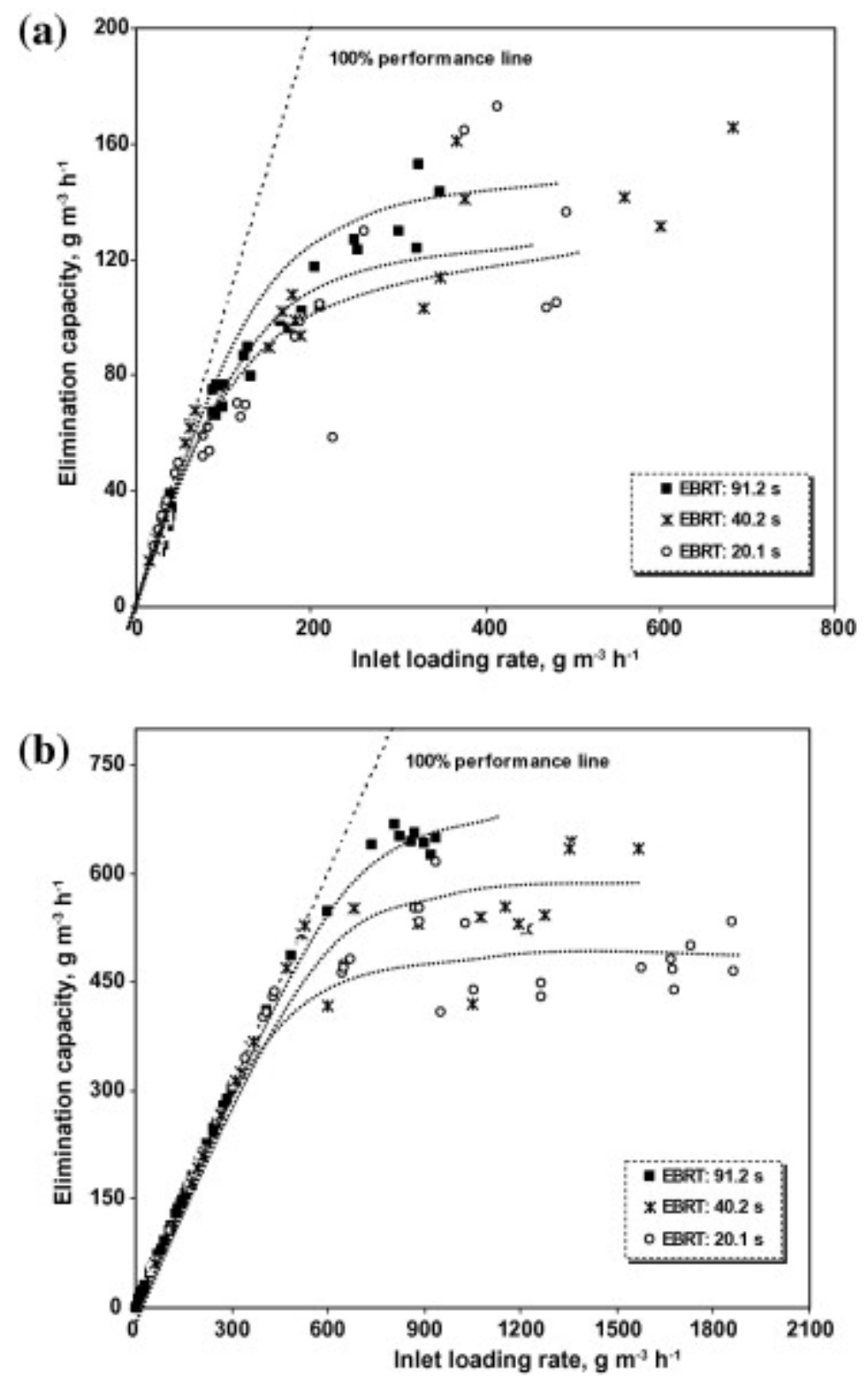

Fig. 4.

EC of the BTF as a function of styrene load at different EBRTs, (a) without silicone oil, and (b) with silicone oil.

\subsubsection{With silicone oil}

As illustrated in Fig. 4b, at an EBRT of $91.2 \mathrm{~s}$, for ILR $<600 \mathrm{~g} \mathrm{~m}^{-3} \mathrm{~h}^{-1}$, nearly $100 \%$ styrene was removed. After that, for ILR varying between 736 and $940 \mathrm{~g} \mathrm{~m}^{-3} \mathrm{~h}^{-1}$, the EC stabilized between 625 and $670 \mathrm{~g} \mathrm{~m}^{-3} \mathrm{~h}^{-1}$. However, at an EBRT of $40.2 \mathrm{~s}$, the 
critical ILR to reach more than 90\% RE was $\sim 525 \mathrm{~g} \mathrm{~m}^{-3} \mathrm{~h}^{-1}$. For ILR $>680 \mathrm{~g} \mathrm{~m}^{-3} \mathrm{~h}^{-1}$, the EC values varied between 550 and $635 \mathrm{~g} \mathrm{~m}^{-3} \mathrm{~h}^{-1}$, depending on the ILR (phase-II). The EC values varied between 400 and $550 \mathrm{~g} \mathrm{~m}^{-3} \mathrm{~h}^{-1}$ for ILR $>650 \mathrm{~g} \mathrm{~m}^{-3} \mathrm{~h}^{-1}$ in phaseIII, which also corresponds to the highest ILR tested $\left(1860 \mathrm{~g} \mathrm{~m}^{-3} \mathrm{~h}^{-1}\right)$. The $\mathrm{ILR}_{\text {critical was }}$ $\sim 600 \mathrm{~g} \mathrm{~m}^{-3} \mathrm{~h}^{-1}$ at an EBRT of $90.1 \mathrm{~s}$, while it dropped to 527 and $\sim 435 \mathrm{~g} \mathrm{~m}^{-3} \mathrm{~h}^{-1}$ at EBRT of 40.2 and 20.1 s, respectively.

\subsection{Comparison of EC values with literature}

The $\mathrm{EC}_{\max }$ achieved in this study for BTF operation without and with silicone oil were 172.8 and $670 \mathrm{~g} \mathrm{~m}^{-3} \mathrm{~h}^{-1}$, respectively (Fig. 4a and b). The BTF performance without silicone oil is comparable to some of the literature reports on gas-phase styrene or other VOC removal, in terms of; (i) bioreactor configurations such as BF, BTF and monolith bioreactor, and (ii) the type of inoculum used in bioreactors, i.e., mixed culture, bacteria or fungi (Weber and Hartmans, 1996, Hwang et al., 2008, Jorio et al., 2009, Rene et al., 2010a and Rene et al., 2010b). In our previous work, using the same fungus (Sporothrix sp.), the $\mathrm{EC}_{\max }$ in a $\mathrm{BF}$ was $336 \mathrm{~g} \mathrm{~m}^{-3} \mathrm{~h}^{-1}$, with $65 \%$ removal ( Rene et al., 2010a), while the $\mathrm{EC}_{\max }$ in a monolith bioreactor was $67 \mathrm{~g} \mathrm{~m}^{-3} \mathrm{~h}^{-1}$, with more than $90 \% \mathrm{RE}$ ( Rene et al., 2010b). It is noteworthy to mention that, the operational mode in all these reactor configurations are different, and the performance of the system in terms of $\mathrm{EC}_{\max }$ then follows the order; BF $>$ BTF $>$ monolith bioreactor. Hwang et al. (2008) designed a novel agitating-type BTF, to avoid clogging problems, and treated styrene vapors at ILR ranging from 20 to $300 \mathrm{~g} \mathrm{~m}^{-3} \mathrm{~h}^{-1}$. The BTF, inoculated with a pure culture of the gram-positive bacterium Brevibacillus sp. SP1, showed an $\mathrm{EC}_{\max }$ of $125 \mathrm{~g} \mathrm{~m}^{-3} \mathrm{~h}^{-1}$. A few papers have also compared bioreactor performance (EC $\max$ values), in terms of fungal or bacterial inoculation. Weber and Hartmans (1996) observed higher EC in a BTF treating gas-phase toluene and inoculated with fungi $\left(45 \mathrm{~g} \mathrm{~m}^{-3} \mathrm{~h}^{-1}\right)$ than in a BTF inoculated with bacterial cultures $\left(28 \mathrm{~g} \mathrm{~m}^{-3} \mathrm{~h}^{-1}\right)$. Jorio et al. (2009) compared gas-phase xylene removal performance in three identical wood chip BFs inoculated with; (a) bacterial consortium, EVB110, (b) fungal consortium (Phanerochaete chrysosporium and Cladosporium sphaerospermum), and (c) mixture of bacteria and fungi. The results from their study showed superior performance of the fungal BF in terms of the EC $\left(77 \mathrm{~g} \mathrm{~m}^{-3} \mathrm{~h}^{-1}\right)$, when compared to both the bacterial system $\left(58 \mathrm{~g} \mathrm{~m}^{-3} \mathrm{~h}^{-1}\right)$ and the mixed culture system $\left(\sim 40 \mathrm{~g} \mathrm{~m}^{-3} \mathrm{~h}^{-1}\right)$.

The high EC value $\left(670 \mathrm{~g} \mathrm{~m}^{-3} \mathrm{~h}^{-1}\right)$ achieved in this study using a BTF with $2 \%(v / v)$ silicone oil is 5.3 times the $\mathrm{EC}_{\max }$ observed for a BTF inoculated with a pure bacterial strain $\left(125 \mathrm{~g} \mathrm{~m}^{-3} \mathrm{~h}^{-1}\right)$ as reported by Hwang et al. (2008), and 3.8 times the $\mathrm{EC}_{\max }$ of a fungi-inoculated BTF $\left(172.8 \mathrm{~g} \mathrm{~m}^{-3} \mathrm{~h}^{-1}\right)$ used in this study without silicone oil. This high EC can be attributed to the stable mycelial growth of the fungus Sporothrix variecibatus and its ability to use lava rock as a suitable support matrix, as well as the presence of silicone oil in the trickling medium that helped to enhance pollutant mass transfer. Silicone oil shows several favorable thermodynamic properties ( Darracq et al., 2009). It acts both as a styrene absorbing and controlled delivery medium and as a surface-active agent to lower the surface tension of water in the trickling phase. Though the phenomenon of mass transfer of styrene or oxygen from the gas to the water phase in the presence of silicone oil is not well understood in BTFs, silicone oil tends to increase the gaseous specific surface area thereby increasing the transfer of styrene from the gasphase to the liquid/biofilm phase ( Dumont et al., 2006). According to Littlejohns and Daugulis (2008), in the presence of silicone oil, the target pollutants are metabolized in 
the aqueous (organic) phase and are continuously delivered from the sequestering phase depending on the demand of the microorganisms and the maintenance of thermodynamic equilibrium between the two phases.

Recently, a silicone oil (20\% w/w) coated perlite BF was tested for $\alpha$-pinene removal and an EC value of $\sim 50 \mathrm{~g} \mathrm{~m}^{-3} \mathrm{~h}^{-1}$ was observed. It was reported that coating the perlite with silicone oil only improved the performance slightly when compared to the BF operation without silicone oil $\left(45 \mathrm{~g} \mathrm{~m}^{-3} \mathrm{~h}^{-1}\right)$ (Hejazi et al., 2010). In the case of a perlite biofilter inoculated with Fusarium solani for hexane removal, the addition of 5\% silicone oil increased the EC from 110 to $180 \mathrm{~g} \mathrm{~m}^{-3} \mathrm{~h}^{-1}$ with $90 \%$ RE ( Arriaga et al., 2006). There is however only one report for styrene removal in a BTF, inoculated with a well-identified mixed culture on lava rock that compares the reactor's performance without and with silicone oil. Djeribi et al. (2005) immersed lava rock grains into silicone oil for $1 \mathrm{~h}$ and used that lava rock, containing the adsorbed silicone oil, as the packing material in a BTF, as an alternative bi-phasic system strategy to treat gas-phase styrene. The inoculum for the BTF was an isolated consortium, containing different strains of Pseudomonas spp., and Achromobacter spp., previously obtained from a twophase CSTB treating styrene. The results from that study showed that, for an ILR of $2980 \mathrm{~g} \mathrm{~m}^{-3} \mathrm{~h}^{-1}$, the RE was $>97 \%$ with an $\mathrm{EC}_{\max }$ of $2900 \mathrm{~g} \mathrm{~m}^{-3} \mathrm{~h}^{-1}$. The EC reported by Djeribi et al. (2005) for styrene removal is the highest achieved so far with biological treatment systems, as evident from a recent literature review on styrene removal in BTF, BF and monolith bioreactors ( Rene et al., 2010b). Similar high BTF performance has been reported in the literature for the biotreatment of $\alpha$-pinene vapors using the fungus Ophiostoma stenoceras as the dominant microorganism ( Montes et al., 2010). In that study, the addition of 5\% silicone oil to the BTF improved the EC more than ten-fold $\left(\mathrm{EC}_{\max }-3249 \mathrm{~g} \mathrm{~m}^{-3} \mathrm{~h}^{-1}\right.$ ) with $>98 \% \mathrm{RE}$, compared to the BTF without silicone oil $\left(\mathrm{EC}_{\max }-232 \mathrm{~g} \mathrm{~m}^{-3} \mathrm{~h}^{-1}\right)$. After analyzing these results, it is clearly evident that the addition of silicone oil not only increases the $\mathrm{EC}_{\max }$ of the BTF multi-fold, but also increases gas-phase styrene bioavailability for the Sporothrix spp., attached to the lava rock. The continuous presence of silicone oil could enhances biodegradation by increasing oxygen transfer to the microorganisms as the solubility of oxygen in silicone oil is roughly 30 times higher than in water ( Arriaga et al., 2006).

\subsection{Pressure drop variations}

\subsubsection{Without silicone oil}

In this study, during the acclimation phase, the $\Delta P$ was $<0.6 \mathrm{~cm} \mathrm{H}_{2} \mathrm{O} \mathrm{m}{ }^{-1}$ bed height, and at that stage the biofilm was still at its early stage of formation. However in phase-I, when the inlet concentration was slowly increased the biomass concentration also increased, leading to an increase in the $\Delta P$ values to $1.3 \mathrm{~cm} \mathrm{H}_{2} \mathrm{O} \mathrm{m}^{-1}$ bed height on day 43, and $\sim 3.6 \mathrm{~cm} \mathrm{H}_{2} \mathrm{O} \mathrm{m}^{-1}$ bed height on day 60 ( Fig. 5a). On the 60th day, a part of the biomass was removed by increasing the liquid trickling rate 4 -fold for $2 \mathrm{~h}$ from 50 to $190 \mathrm{ml} \mathrm{min}^{-1}$, without recycling the leachate, thereby reducing the $\Delta P$ to $2 \mathrm{~cm} \mathrm{H}_{2} \mathrm{O} \mathrm{m}^{-1}$ bed height. Many approaches have been proposed in the literature to reduce pressure drop in BTFs, which include biomass control by chemical, biological and physical/mechanical means ( Kennes and Veiga, 2002, Mendoza et al., 2004, Hwang et al., 2008 and Yang et al., 2010). Among the physical methods, filling the BTF with water and draining, back-washing, disturbing the packing material and air sparging are possible solutions to remove excess biomass ( Mendoza et al., 2004). Again, when the 
$\triangle P$ increased from 1.9 to $12 \mathrm{~cm} \mathrm{H}_{2} \mathrm{O} \mathrm{m}^{-1}$ bed height due to biomass clogging (days 7583) in phase-II, the BTF operation was stopped intermittently for $4 \mathrm{~d}$, and the reactor was re-packed to eliminate a substantial part of excess biomass. Thereafter in phase-III, the $\Delta P$ remained at lower values ( $<4 \mathrm{~cm} \mathrm{H}_{2} \mathrm{O} \mathrm{m}{ }^{-1}$ bed height).

(a)

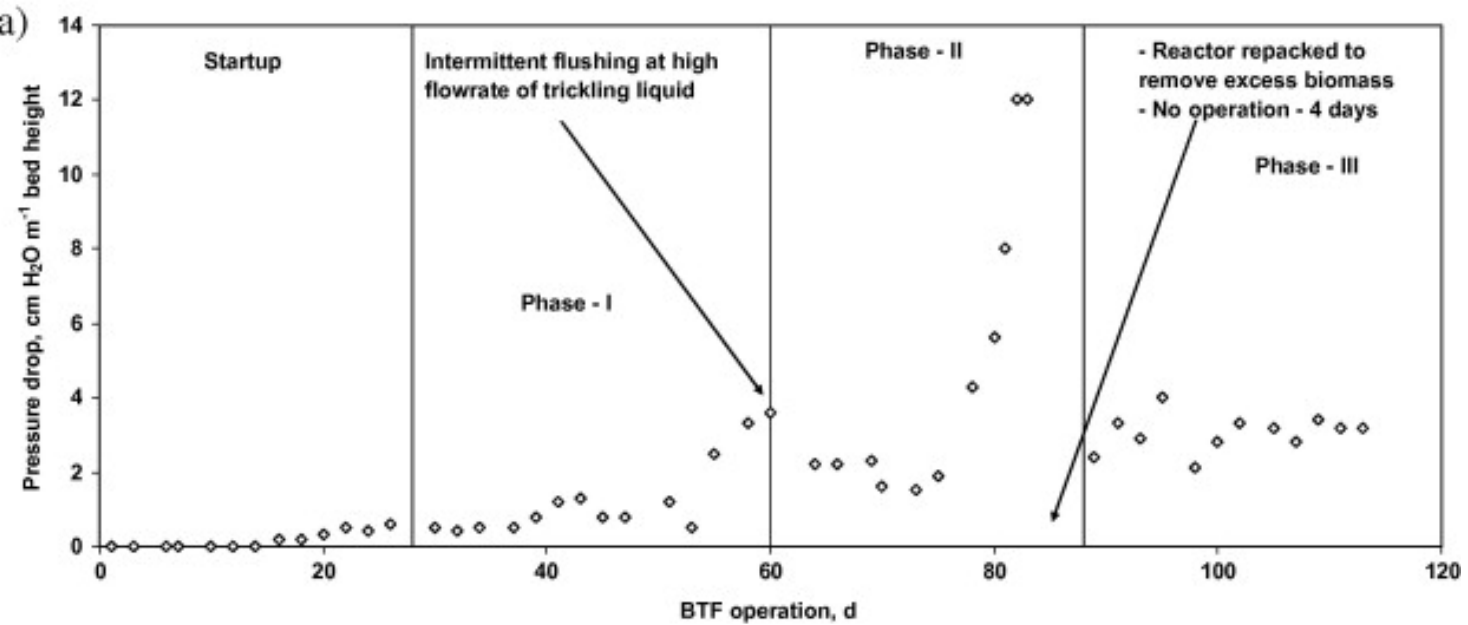

(b)

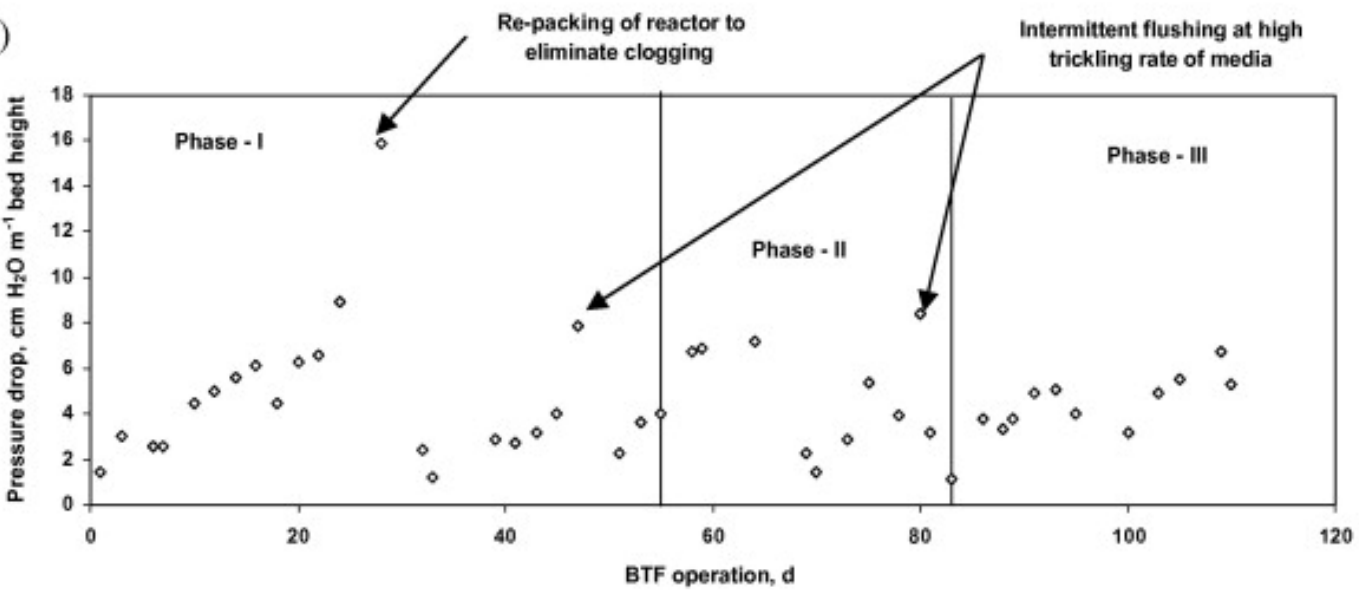

Fig. 5.

Variation of $\Delta P$ as a function of BTF operation, (a) without silicone oil, and (b) with silicone oil.

\subsubsection{With silicone oil}

Because of the absence of a long start-up phase in the BTF operation with silicone oil and because of the presence of significant attached biomass from day 1 as described before, the $\Delta P$ values were higher $\left(2.5 \mathrm{~cm} \mathrm{H}_{2} \mathrm{O} \mathrm{m}^{-1}\right.$ bed height) than without oil ( Fig. $5 b)$. The presence of $10 \%$ silicone oil $(\mathrm{v} / \mathrm{v})$ in the trickling liquid led to a well-coalesced emulsion of fungi and silicone oil, and this emulsion was constantly present in the trickling liquid that contributed to high $\Delta P$ values, in comparison to BTF operation without silicone oil. The $\Delta P$ started to increase from $\sim 4.5 \mathrm{~cm} \mathrm{H}_{2} \mathrm{O} \mathrm{m}^{-1}$ bed height on day 10 to $\sim 8.9 \mathrm{~cm} \mathrm{H}_{2} \mathrm{O} \mathrm{m}^{-1}$ bed height during the next 17 days of operation. However, on the 28th day, the $\Delta P$ showed a 2-fold increase abruptly, leading to flooding conditions near the inlet of the filter bed. After intermittent shut-down for maintenance, during re-start (day 32), the nutrient medium was replaced completely and the silicone oil proportion was also reduced from $10 \%$ to $2 \%(v / v)$. This strategy, i.e., lowering the 
volume ratio of silicone oil, was experimented to prevent thick biomass-emulsion formation, reduce $\Delta P$ and avoid severe maintenance problems. For the remaining part of this study, experiments were continued with $2 \%$ silicone oil $(v / v)$, as it appeared to be sufficient for gas-phase styrene transfer and for reaching high RE almost instantly after re-start $(100 \%)$. Though there are no written rules on how much silicone oil should be added to a BTF, it appears from this study that switching the BTF operation from $10 \%$ to $2 \%$ silicone oil would prolong stable BTF operation, while maintaining a very high performance. This aspect is very important, as operating the BTF with a low oil ratio will allow maintaining low operating costs.

\subsection{Effect of transient-state operations}

\subsubsection{Without silicone oil}

The microorganisms in waste-gas treatment systems can generally sustain sudden, yet medium shock-loads well. In general, fungi inoculated bioreactors have shown good resistance to transient conditions, for hydrophobic VOCs, compared to bacterial systems (Kennes and Veiga, 2001). In this study, a 6-h short-term shock-load was induced to the BTF without silicone oil, at an EBRT of $20.1 \mathrm{~s}$ (Fig. 6a). The styrene concentration was kept low prior to the shock, at $0.4 \mathrm{~g} \mathrm{~m}^{-3}$, and suddenly increased to $2.3 \mathrm{~g} \mathrm{~m}^{-3}$ during the 6-h shock test. The BTF was thus subjected to a 5-fold increase in the ILR from 80 to $400 \mathrm{~g} \mathrm{~m}^{-3} \mathrm{~h}^{-1}$, and it was observed that the RE decreased from $\sim 80 \%$ to a minimum of $20 \%$. During this shock-load, the EC increased 2-fold, from an original medium value of $60-120 \mathrm{~g} \mathrm{~m}^{-3} \mathrm{~h}^{-1}$. When the ILR was reduced and brought back to original values, the EC decreased, while the RE gradually improved. The response of the BTF was fast as seen from the immediate decrease in RE during the shock-load, and, when pre-shock steady-state conditions were restored, the RE started to increase positively. This observation shows the resilience nature of the BTF, and the ability of the Sporothrix sp., to resist harsher operating conditions. 

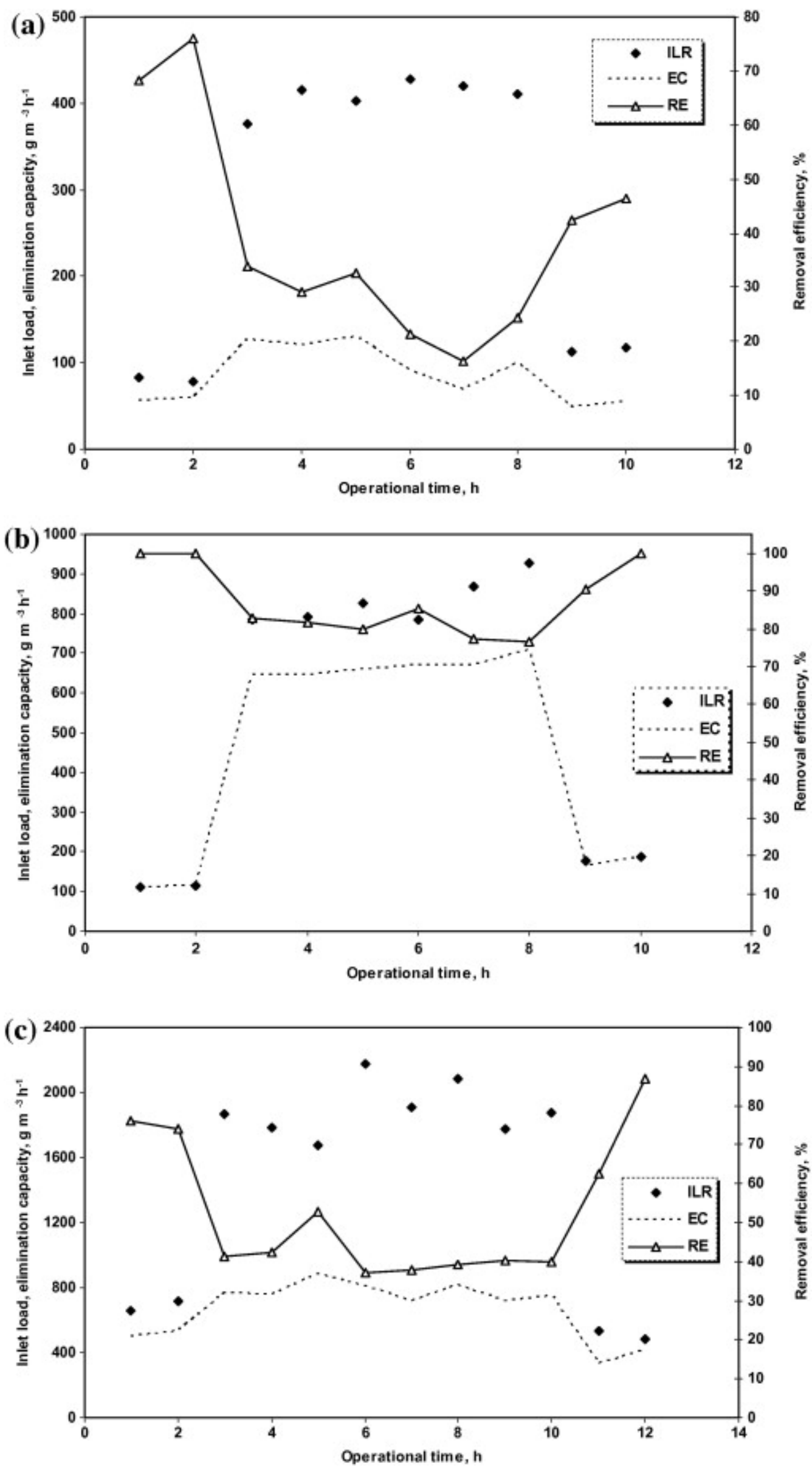
Fig. 6.

Effect of short-term shock-loads on the performance of the BTF, (a) 8-h shockload, without silicone oil, (b) 6-h low to medium load with silicone oil, and (c) 8-h medium to high load with silicone oil.

\subsubsection{With silicone oil}

Two shock-load experiments were conducted with the BTF operating with silicone oil $(2 \% \mathrm{v} / \mathrm{v})$, one as short-term (6-h) low to medium shock-load, and the second as shortterm (8-h) medium to high load fluctuation, at an EBRT of $20.1 \mathrm{~s}$ ( Fig. 6b and c). Higher overloads were studied in the system without silicone oil ( Fig. 6a), because a much higher performance was already reached at high loads under steady-state conditions in presence of the oil-phase. The inlet concentration was kept at low values $\left(0.6 \mathrm{~g} \mathrm{~m}^{-3}\right)$ prior to the 6-h shock-load, corresponding to an ILR of $110 \mathrm{~g} \mathrm{~m}^{-3} \mathrm{~h}^{-1}$, with basically $100 \%$ removal of styrene. The ILR was then increased to $880 \mathrm{~g} \mathrm{~m}^{-3} \mathrm{~h}^{-1}$ during the shock-load, and it was observed that the RE dropped suddenly, but only by $\sim 20 \%$. During this phase of shock-load, the EC increased from an original low value of 110 $670 \mathrm{~g} \mathrm{~m}^{-3} \mathrm{~h}^{-1}$ and then remained almost constant during the 6-h medium shock-load ( Fig. 6b). However, when the BTF was subjected to a higher shock-load $\left(1900 \mathrm{~g} \mathrm{~m}^{-3} \mathrm{~h}^{-1}\right)$ from a medium load of $\sim 670 \mathrm{~g} \mathrm{~m}^{-3} \mathrm{~h}^{-1}$, the RE dropped suddenly, from $75 \%$ to $\sim 40 \%$ and then remained almost constant at such value during the shock-load period of 8-h ( Fig. 6c). Such decrease in RE is nevertheless still lower than in the system without silicone oil, despite the much higher overload used in the present experiment. The EC increased from 530 to $850 \mathrm{~g} \mathrm{~m}^{-3} \mathrm{~h}^{-1}$ during the shock-load compared to its value before the shock-load. The highest ILR tested during the short-term shock-load was certainly higher than the ILR tested under steady-state operations (phase-III), where the $\mathrm{EC}_{\max }$ was only $535 \mathrm{~g} \mathrm{~m}^{-3} \mathrm{~h}^{-1}(\mathrm{RE}-29 \%)$. The results show that the fungal BTF with $2 \%(\mathrm{v} / \mathrm{v})$ silicone oil has the ability to handle high shock-loads much better $\left(>1900 \mathrm{~g} \mathrm{~m}^{-3} \mathrm{~h}^{-1}\right.$ with $40 \% \mathrm{RE}$ ) than the BTF without silicone oil, and the attached biomass as well as the addition of silicone oil showed good resilience property in terms of performance revival during the post-shock stage. The values of EC achieved under transient conditions in the BTF with silicone oil (670 and $850 \mathrm{~g} \mathrm{~m}^{-3} \mathrm{~h}^{-1}$ ), are comparable to the $\mathrm{EC}_{\max }$ $\left(670 \mathrm{~g} \mathrm{~m}^{-3} \mathrm{~h}^{-1}\right.$ ) achieved for that reactor under normal loading conditions.

Further work in this area is suggested, namely; investigation on the interaction between silicone oil and microorganism, modeling the two-liquid phase BTF, studies pertaining to the survival of microorganisms on the surface of the packing in presence of silicone oil, and identifying pollutant-microorganism interactions during the removal of mixtures of hydrophobic VOCs in two-liquid phase BTFs.

\section{Conclusions}

The results from this study show the operational advantages and limitations of one and two-liquid phase fungal BTF to handle low and high styrene loads under both steady and transient-state operations. The addition of an organic phase (silicone oil) in the BTF enhanced the transfer rate of gas-phase styrene into the biofilm, thereby improving the styrene removal performance. For ILRs $<94.5 \mathrm{~g} \mathrm{~m}^{-3} \mathrm{~h}^{-1}$ (BTF without oil) and $600 \mathrm{~g} \mathrm{~m}^{-3} \mathrm{~h}^{-1}$ (BTF with oil) $>90 \% \mathrm{RE}$ was achieved. Decreasing the silicone oil proportion in the aqueous phase from $10 \%$ to $2 \%(\mathrm{v} / \mathrm{v})$ helped to overcome the clogging 
problem without affecting the reactors performance. During shock-load tests, despite subjecting the two-liquid phase BTF to much higher styrene overloads (ILR $2000 \mathrm{~g} \mathrm{~m}^{-3} \mathrm{~h}^{-1}$ ) than without oil, the RE decreased by only $50 \%$, reaching a better and more stable performance in the two-liquid phase reactor than in the system without oil.

\section{Acknowledgements}

The support from the Spanish Ministry of Science and Innovation (Project CTM200762700/TECNO) and European FEDER funds is greatly acknowledged. M. Montes thanks the UDC for her Ph.D fellowship. E.R. Rene thanks the Spanish Ministry of Science and Innovation for his research contract (JCI-2008-03109).

\section{References}

J.M. Aldric, P. Thonart

Performance evaluation of a water/silicone oil two-phase partitioning bioreactor using Rhodococcus erythropolis T902.1 to remove volatile organic compounds from gaseous effluents

J. Chem. Technol. Biotechnol., 83 (2008), pp. 1401-1408

S. Arriaga, R. Muñoz, S. Hernández, B. Guieysse, S. Revah

Gaseous hexane biodegradation by Fusarium solani in two liquid phase packed-bed and stirred tank bioreactors

Environ. Sci. Technol., 40 (2006), pp. 2390-2395

S. Arriaga, S. Revah

Removal of $n$-hexane by Fusarium sp. with a gas phase biofilter

J. Ind. Microbiol. Biotechnol., 32 (2005), pp. 548-553

A. Avalos-Ramirez, J.P. Jones, M. Heitz

Control of methanol vapours in a biotrickling filter: performance analysis and experimental determination of partition coefficient

Bioresour. Technol., 100 (2009), pp. 1573-1581

L. Bailón, M. Nikolausz, M. Kästner, M.C. Veiga, C. Kennes

Removal of dichloromethane from waste gases in one- and two-liquid-phase stirred tank bioreactors and biotrickling filters

Water Res., 43 (2009), pp. 11-20

J.M. Chen, R.Y. Zhu, W.B. Yang, L.L. Zhang

Treatment of a BTo-X-contaminated gas stream with a biotrickling filter inoculated with microbes bound to a wheat bran/red wood powder/diatomaceous earth carrier Bioresour. Technol., 101 (2010), pp. 8067-8073 
G. Darracq, A. Couvert, C. Couriol, Y. Amrane, D. Thomas, E. Dumont, Y. Andres, P. Le Cloirec

Silicone oil: an effective absorbent for the removal of hydrophobic volatile organic compounds

J. Chem. Technol. Biotechnol., 85 (2009), pp. 309-313

A.J. Daugulis

Partitioning bioreactors

Curr. Opin. Biotechnol., 8 (1997), pp. 169-174

R. Djeribi, T. Dezenclos, A. Pauss, A.J. Lebeault

Removal of styrene from waste gas using a biological trickling filter

Eng. Life Sci., 5 (2005), pp. 450-457

B.J. Dowty, J.L. Laseter, J. Storet

The transplacental migration and accumulation in blood of volatile organic constituents

Pediatric Res., 10 (1976), pp. 696-701

E. Dumont, Y. Andrès, P. Le Cloirec

Mass transfer coefficients of styrene and oxygen into silicone oil emulsions in a bubble reactor

Chem. Eng. Sci., 61 (2006), pp. 5612-5619

E. Estévez, M.C. Veiga, C. Kennes

Biodegradation of toluene by the new fungal isolates Paecilomyces variotii and Exophiala oligosperma

J. Ind. Microbiol. Biotechnol., 32 (2005), pp. 33-37

P. Hejazi, F. Borenberg, G. Işik, K. Rupar-Gadd, G. Strandmark, S.A. Shajaosadati, U. Welander

Treatment of $\alpha$-pinene-contaminated air using silicone oil-coated perlite biofilter

Environ. Prog. Sustain. Energy, 9 (2010), pp. 313-318

J.W. Hwang, C.Y. Choi, S.-H. Park, E.-Y. Lee

Biodegradation of gaseous styrene by Brevibacillus sp. using a novel agitating biotrickling filter

Biotechnol. Lett., 30 (2008), pp. 1207-1212

H. Jorio, L. Bibeau, M. Heitz

Biofiltration of air contaminated by styrene: effect of nitrogen supply, gas flow rate and inlet concentration

Environ. Sci. Technol., 34 (2000), pp. 1764-1771

H. Jorio, Y. Jin, H. Elmrini, J. Nikiema, R. Brzezinski, M. Heitz

Treatment of VOCs in biofilters inoculated with fungi and microbial consortium

Environ. Technol., 30 (2009), pp. 477-485

C. Kennes, E.R. Rene, M.C. Veiga

Bioprocesses for air pollution control

J. Chem. Technol. Biotechnol., 84 (2009), pp. 1419-1436 
C. Kennes, M.C. Veiga

Bioreactors for Waste Gas Treatment

Kluwer Academic Publishers, Dordrecht, The Netherlands (2001)

Kennes and Veiga, 2002

C. Kennes, M.C. Veiga

Inert filter media for the biofiltration of waste gases - characteristics and biomass control

Rev. Environ. Sci. Biotechnol., 1 (2002), pp. 201-214

C. Kennes, M.C. Veiga

Fungal biocatalysts in the biofiltration of VOC polluted air

J. Biotechnol., 113 (2004), pp. 305-319

Kirk-Othmer, 1983. Encyclopedia of Chemical Technology, third ed., vol. 21. Wiley, New York.

J.V. Littlejohns, A.J. Daugulis

Response of a solid-liquid two-phase partitioning bioreactor to transient BTEX loadings Chemosphere, 73 (2008), pp. 1453-1460

J.A. Mendoza, O.J. Prado, M.C. Veiga, C. Kennes

Hydrodynamic behaviour and comparison of technologies for the removal of excess biomass in gas-phase biofilters

Water Res., 38 (2004), pp. 404-413

M. Montes, M.C. Veiga, C. Kennes

Two-liquid-phase mesophilic and thermophilic biotrickling filters for the biodegradation of $\alpha$-pinene

Bioresour. Technol., 101 (2010), pp. 9493-9499

M. Montes, A.J. Daugulis, M.C. Veiga, C. Kennes

Characterization of absorbent polymers for the removal of volatile hydrophobic pollutants from air

J. Chem. Technol. Biotechnol., 86 (2011), pp. 47-53

R. Muñoz, S. Arriaga, S. Hernandez, B. Guieysse, S. Revah

Enhanced hexane biodegradation in a two phase partitioning bioreactor: overcoming pollutant transport limitations

Proc. Biochem., 41 (2006), pp. 1614-1619

J. Paca, M. Halecky, M. Fitch

Steady-state performance of an activated carbon biofilter degrading styrene: effects of residence time and inlet concentration

J. Air Waste Manage. Assoc., 59 (2009), pp. 45-51 
M. Ramírez, J.M. Gómez, G. Aroca, D. Cantero

Removal of hydrogen sulfide by immobilized Thiobacillus thioparus in a biotrickling filter packed with polyurethane foam

Bioresour. Technol., 100 (2009), pp. 4989-4995

\section{Article}

E.R. Rene, M.C. Veiga, C. Kennes

Performance of a biofilter for the removal of high concentrations of styrene under steady and non-steady state conditions

J. Hazard. Mater., 168 (2009), pp. 282-290

E.R. Rene, M.C. Veiga, C. Kennes

Biodegradation of gas-phase styrene using the fungus Sporothrix variecibatus: impact of pollutant load and transient operation

Chemosphere, 79 (2010), pp. 221-227

E.R. Rene, M.E. Lopez, M.C. Veiga, C. Kennes

Performance of a fungal monolith bioreactor for the removal of styrene from polluted air

Bioresour. Technol., 101 (2010), pp. 2608-2615

A.K. Shukla, R.S. Singh, S.N. Upadhyay, S.K. Dubey

Kinetics of bio-filtration of trichloroethylene by methanotrophs in presence of methanol

Bioresour. Technol., 101 (2010), pp. 8119-8126

J.W. van Groenestijn, N.J.R. Kraakman

Recent developments in biological waste gas purification in Europe

Chem. Eng. J., 113 (2005), pp. 85-91

J.W. van Groenestijn, W.N.M. van Heiningen, N.J.R. Kraakman

Biofilters based on the action of fungi

Water Sci. Technol., 44 (9) (2001), pp. 227-232

F.J. Weber, S. Hartmans

Prevention of clogging in a biological trickle-bed reactor removing toluene from contaminated air

Biotechnol. Bioeng., 50 (1996), pp. 91-97

C. Yang, H. Chen, G. Zeng, G. Yu, S. Luo

Biomass accumulation and control strategies in gas biofiltration

Biotechnol. Adv., 28 (2010), pp. 531-540

M. Zilli, M.C. Veiga, C. Kennes, A. Converti

Biofilters: air purification

M.C. Flickinger (Ed.), Encyclopedia of Industrial Biotechnology: Bioprocess, Bioseparation and Cell Technology, vol. 1J. Wiley, New York, USA (2010), pp. 617637 